\title{
Romanceiro de Elson Farias: o bardo e o cancioneiro da representação do homem amazônico
}

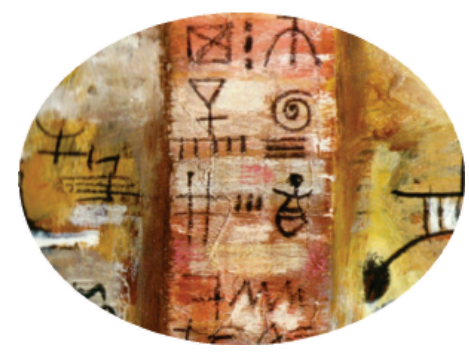

Maria Luiza Germano de Souza*

\section{Resumo}

O objetivo deste estudo é mostrar os quadros pintados na pena do poeta Elson Farias em seu livro Romanceiro. Elson Farias faz, em seus poemas, a representação do homem amazônico, sobretudo o ribeirinho: sincretismo religioso, sexualidade da mulher, existencialismo, seres encantados, fetiches, mitos refigurados e memória.

Palavras-chave: Romanceiro; representação; Amazônia; ribeirinho.

\begin{abstract}
The aim of this study is to show the paintings in the pen of the poet Elson Farias in his book Ballads. Farias makes Elson, in his poems, the representation of the Amazonian man, especially the riverside: religious syncretism, women's sexuality, existentialism, enchanted beings, fetishes, myths and memory refigurados.
\end{abstract}

Keywords: Ballads; representation; Amazon; riverine.

\footnotetext{
* Mestra em Sociedade e Cultura na Amazônia pela Universidade Federal do Amazonas (UFAM). Especialista em Literatura Brasileira Moderna e Pós-Moderna (UFAM). Professora Assistente de Língua Portuguesa da Unidade Acadêmica Permanente de Itacoatiara. Pertence ao Grupo de Estudos e Pesquisas em Literaturas de Língua Portuguesa - GEPELIP - UFAM. 


\section{Breve história dos romanceiros}

A palavra romanceiro, segundo Massaud Moisés (1999, p. 451), refere-se à romance (romant, rimance) e é um poema narrativo medieval (século XIII) “de origem popular e tipicamente espanhol”, que busca nos feitos heroicos da pátria e do povo sua fonte de inspiração. Fruto de várias influências, do épico às baladas, nos seus versos encontramos as mais variadas temáticas.

Não devemos confundir "romance" com os "romances em prosa", pois estes são narrativos e pertencem ao gênero épico. O épico, segundo Hênio Tavares (1981), tem como base a narração, podendo apresentar-se em verso ou em prosa (romance, epopeia, balada, novela, conto, crônica, canção de gesta etc.); e aqueles (romance/romanceiro), integram o gênero lírico. Romance é cada um dos poemas que compõe um romanceiro e o romanceiro propriamente dito constitui-se, dessa maneira, em coletivo de romance, "conjunto deles todos (romances), bem como as antologias ou coletâneas nos quais são publicados" (TAVARES, 2005, p. 75).

No Brasil, as heranças que temos do gênero nos chegaram via Portugal e Espanha, o que pode ser percebido no Romanceiro Popular do Nordeste. A base do romanceiro nordestino é oral, sendo sua forma mais conhecida o cordel. Outra direção assumida pelos romanceiros, que perdeu a forma de versos, transformando-se em histórias contadas por algumas pessoas, são as "histórias de Trancoso", "História da baratinha" e "Contos da Carochinha". Assim, o Nordeste brasileiro é responsável por ter dado outra roupagem e dimensão ao romanceiro tradicional ibérico, desde os aspectos concernentes aos assuntos, bem como a estrutura formal.

$\mathrm{Na}$ atualidade, os romanceiros perderam a base oral, mas alguns aspectos formais sobreviveram. Um desses aspectos é uso dos versos de sete sílabas (heptassílabos ou redondilha maior) e os de cinco sílabas (pentassílabos ou redondilha menor), porque são versos simples, melódicos e de fácil assimilação. Norma Goldstein (2000) diz que é por isso que tais versos fazem parte e são utilizados nas canções populares e folclóricas do Brasil e de Portugal, e também foram bastante usados pelos trovadores medievais. Os romanceiros modernos

152 Somanlu, ano 11, n. 1, jan./jun. 2011 
já não trazem a marca maior dos romanceiros ibéricos: a disseminação oral entre os bardos e o povo, a literatura oral, portanto. A eles (romanceiros modernos) é mais próprio chamá-los de romanceiros artificiais, pois não nasceram no meio do povo. No geral, conhecemos apenas as histórias populares que narram, mas as narrações chegaram ao nosso conhecimento por via escrita.

O Romanceiro de Elson Farias, ora apresentado aqui, teve a primeira edição em 1985, portanto pertence à poesia contemporânea. Entretanto, conservou dos romanceiros tradicionais ibéricos a forma poética no uso da redondilha e a escolha das temáticas que privilegia no seu livro: temas populares. Os assuntos-base são amazônicos das pessoas que vivem nos beiradões. O poeta canta a expressão cabocla ${ }^{1}$ vivificada por meio de suas histórias, lendas, mitos, "causos", crendices, ou seja, evoca elementos do povo, principalmente o ribeirinho, e vai tecendo um painel de vastos acontecimentos e impressões, sempre na ótica popular.

\section{Elson Farias: o "bardo" e o regionalismo}

Elson Farias (1936) nasceu no interior do Amazonas, em Roseiral, município de Itacoatiara, e é um dos poetas amazonenses mais produtivos na atualidade. $\mathrm{O}$ referido autor viveu no interior até os dezoito anos. Fixou-se em Manaus, onde realizou seus primeiros estudos. Participou ativamente da movimentação que se seguiu à fundação do Clube da Madrugada - o "Clube" foi uma reação ao academicismo da época e nasceu com a proposta de renovar e atualizar a literatura regional.

A biografia literária de Elson Farias é vasta e tem por base o recorte de uma literatura eminentemente local, que privilegia aspectos de seu locus de origem e de sua experiência de vida. Assim, confirma-se sua inserção na linha temática de um regionalismo chamado de pitoresco, porque o veio norteador que serve para a composição de grande parte de seus livros e do Romanceiro, em especial, é a terra natal e sua gente. Ele canta o local em seus vários matizes: constrói quadros amazônicos compostos por meio "de aspectos da vida amazônica, a cor, o cheiro, o paladar." E ainda: "Meu esforço é integrar 
aspectos da paisagem e do homem amazônico no panorama da cultura da língua, porque afinal esta é a terra do poeta" (FARIAS, 2006, p. 140-148).

\section{O Romanceiro}

Na primeira edição do Romanceiro, 1985, havia vinte e cinco romances entremeados de oito falas ou assuntos, e oito títulos, perfazendo trinta e três poemas. Na edição de 1990, foram acrescidos cinco poemas: "O rio Amazonas" e os "Quatro romances dos senhores do lugar", totalizando vinte e nove romances e nove falas introdutórias, portanto trinta e oito poemas. Somente os romances contam histórias, as falas são elos para o que vai ser narrado. Esse modo incomum de tessitura do livro pode levar o poeta a fazer novas edições com a inserção de mais poemas e/ou romances. O que nos leva a crer que o Romanceiro seja um livro inconcluso, uma vez que a história do homem também o é.

Há um grupo de poemas que se reportam à temática DA CHUVA E SEUS MEDOS O medo da chuva assume dimensões inimagináveis na solidão dos rios e florestas amazônicas: "noites de noturna angústia,/ noites de angústia noturna,/ só chuva e chuva três dias,/ três noites insones, frias." (FARIAS, IBID., p. 21)

Nos poemas que constam a temática da chuva e seus medos vislumbramos dois antagonismos: o primeiro é o medo que a chuva e as enchentes causam, os males próprios do que vem depois das enchentes (as febres, os mosquitos); o segundo é que, passadas as chuvas, vem a abundância do pescado e, com isso, a fartura para o ribeirinho: "Meio-dia a nossa mesa/era posta para todos,/peixe e peixe, cheiro-verde,/ limão, pimenta, alfavaca". (IBID., p. 20).

$\mathrm{Na}$ perspectiva de um regionalismo que privilegia os elementos eminentemente locais, nos deparamos com um poeta-trovador que espalha o olhar e alcança os matizes da vida interiorana nas suas várias gradações.

O Romanceiro tem uma divisão de assuntos feita em blocos elegidos pelo escritor: da morte pela água; da chuva e seus medos; dos heróis sem

154 Somanlu, ano 11, n. 1, jan./jun. 2011 
nome; da fartura das águas; seis romances de outras sortes; três romances da infância; três romances do meu tio Luís; quatro romances dos senhores do lugar e três episódios do rio. Todavia, a divisão escolhida, feita por nós para esta análise, será outra: temas existenciais; seres encantados/encantarias, fetiches; mitos refigurados; memória e sexualidade.

\section{Temas existenciais}

O primeiro quadro escolhido para verificação de representações do social nos é mostrado por meio da fala inicial “As visões". O título já sugere a ideia de coisas deformadas, nebulosas, indivisas, que enxergamos com certo temor. E é exatamente o que iremos encontrar, porque o autor faz um pequeno inventário das possibilidades de se morrer nos rios locais: afogado, de malária, abandonado pelas instituições, e de como acontece os enterros dos mortos nos beiradões amazônicos: "De estrelas da madrugada/ me cumulava este rio,/ vinha um corpo de afogado/ boiando assim como um boi,/[...]"(IBID, p. 3).

Necessário referir que temos dois tipos de mortes nos romances na divisão da morte pela água. Uma é a morte por afogamento; a outra ocorre quando um barco vai a pique e mata muitas pessoas. Aparentemente são duas mortes iguais, mas não na Amazônia. A morte por afogamento não é a mesma morte que sucede quando um barco soçobra e ceifa muitas vidas. Nesta última há embutido a catástrofe, que assume conotações sociais de maior envergadura, enquanto que uma pessoa se afogando parece somente mais uma pessoa que morre, um episódio qualquer na vida dos ribeirinhos. Assim, depois do naufrágio: "Quando o dia com o sol/ chegou, tudo estava certo,/ corria o rio tranqüilo/ com o corpo descoberto./ Nada houvera acontecido,/ só notícias de um vencido" (IBID, p. 11-12).

É como se a morte pela água assumisse a mesma simbologia do fluir do rio: o destino do homem é certo como o eterno ir e vir das águas, talvez por isso, inconscientemente, a falta de alarde perscrutada no poema. Morreram afogados, soçobrados, mas esse não é o destino dos homens? 
Bachelard (1997, p. 14) assim se refere ao fado (destino) dos seres humanos: "Desaparecer na água profunda ou desaparecer num horizonte longínquo, associar-se à profundidade ou à infinidade, tal é o destino humano que extrai sua imagem do destino das águas." Desse modo, o rio e homem detêm o mesmo jugo, isto é, a submissão à morte.

Em outro poema, o "Romance do afogado", da mesma divisão DA MORTE PELA ÁGUA, tem-se a mesma imagem da relação despretensiosa do ribeirinho com os desditos do rio. Em um primeiro plano, nos deparamos com um homem forte, valente e temido, porque, quando bebia, aterrorizava as crianças. A vida daquele homem, "O afogado", era ritmada pela sua montaria, a canoa era um dos seus motivos usados no dia a dia da sobrevivência: "Remava porque remava,/vivia porque vivia,/só vivia se remava,/remando a vida o temia.” (IBID., p. 9). Esse homem se sente dignificado quando está sobre a canoa, ela é uma espécie de segunda veste e pode ser tida como um símbolo amazônico, devido à grande importância social que tem.

No entanto, "a canoa costumeira/ passou certa vez sem ele". Encontraram-no boiando nas águas do rio e, então, a morte adquire, novamente, a conotação de acontecimento sem importância, repetido: "Boiando entre galhos rotos/ um vulto abriu a flor d'água,/ colheram roído o corpo/ sem os olhos e o nariz/ a manhã chegava alegre,/ tão quanto alegre, feliz.” (IBID., p. 10).

Nos quadros mostrados, na divisão DA MORTE PELA ÁGUA, o rio reproduz a ideia contrária ao seu desígnio, que é o de reproduzir a vida por meio da fartura de sua águas. Mas não esqueçamos que os símbolos carregam a dualidade do positivo e do negativo. Nos poemas mencionados, a temática que predomina é a da morte, portanto ideia negativa do rio. A fartura dos peixes é a metáfora da vida. $\mathrm{E}$ assim, temos a circularidade e ambivalência dos eventos: morte/vida; vida/morte.

\section{Seres encantados, encantarias e fetiches}

Nessa linha temática explorada no Romanceiro, temos a presença do que se chama, na designação proposta por Galvão, os bichos visagentos e os

156 Somanlu, ano 11, n. 1, jan./jun. 2011 
rituais de práticas mágicas feitas pelos curandeiros, figuras sobejadas dos pajés. Existem ainda as categorias que se referem aos gênios das florestas e dos rios, isto é, os entes que assombram os homens (Curupira, Anhangá, Matintaperera, Boto, Cobra-grande e outros) exercendo uma função tão importante quanto os santos para o amazônida, porque carregam conteúdo de verdade para o habitante local e "despertam atitudes emocionais e místicas na mesma intensidade que a do corpo do catolicismo" (GALVÃO, 1976, p. 64).

Os botos, por exemplo, são categorizados como entes encantados, chamados também de "companheiros do fundo" por habitar o fundo dos rios. Por seu turno, os curandeiros exercem a função de médicos, tendo grande prestígio no que fazem, tratando tanto as doenças de corpo quanto as da alma. No poema Romance do Curandeiro, observa-se que o corpo, por ser tributário, é menos importante que a alma: "Vinham de todos os rios/ os doentes de alma e corpo,/ mais de alma que de corpo,/ posto ser o corpo da alma/ tributário, [...] Catingueira/ era o princípio da vida/ ou a força que sustém/ a vida, princípio e fim" (IBID., p. 63).

Temos desenhadas as peculiaridades da prática de cura efetuada pelos curandeiros e a importância de seu papel social nas comunidades amazônicas. Os curandeiros exercem, portanto, o papel não somente de médicos para quem acredita em seus poderes, mas também de guia espiritual. São tão importantes que têm em suas mãos o princípio e o fim da vida de quem os procura.

Já no "Romance do afogado" temos representado o tema do fetiche, outra direção assumida pela ação do imaginário amazônico. A atribuição de poderes mágicos positivos ou negativos a alguns elementos da natureza é uma prática comum efetuada pelo caboclo. Há um conjunto significante desses sobrenaturais evocados na cultura popular amazônica: o muiraquitã, o tajá, a coruja, entre outros. A cuia com vela também é representante dos fetiches e aparece no referido poema/romance. Aqui, a imagem é alargada para inserir a crendice popular de que, ao desaparecer um corpo vítima de afogamento, acha-se o morto colocando uma cuia e dentro uma vela acesa, jogando-a no rio; no local em que a cuia parar, lá estará o afogado, portanto a cuia e a vela acesa assumem poderes de encontrar alguém que morre por afogamento: 
"Lançaram velas de cera/na cuia, sondando o rio,/ mas o vento baixo vinha/ e a magia se perdia" (IBID., p. 9).

\section{Mitos refigurados}

De acordo com Loureiro (1995), o rio e a floresta amazônica têm olhos que espreitam, porque de ambos emergem o que não se explica pela razão ou pela realidade. Ou ainda, o universo sobre o qual se debruça o caboclo, fabulando sobre os elementos mágicos que servem para explicar e dar conta de seu mundo de vivência somente pode ser compreendido por meio do que ele imagina e refigura em crenças, fetiches, rituais, mitos. Desse modo, a floresta tem sido "um lugar de onde o mistério, o desconhecido, o imaginário espreitam com mil olhos. Nela repousam, caminham e vagam santos e visagens. Dela evola sempre uma atmosfera de mistério" (LOUREIRO, 1995, p. 203).

Temos refigurações míticas presentes no Romanceiro que apontam para os propalados mitos universais gregos. Elson Farias, no "Romance da desaparecida", narra o apanágio popular de que está revestido um desses mitos:

\section{I}

A madrugada chegara molhada nessa manhã, água da noite de véspera escura. Coruja e rã o sitio tarde dormia. Desabrochava-se a carne.

De sombra os galhos de sombra feriam de luz mortiça a paisagem da manhã. Corria o rio sem força corria com pouco afã, as nuvens sujas pairavam tal quando canta o cauã. $[\ldots]$ 
III

Desde aí dessa manhã nunca mais ela voltou, seus irmãos desesperaram, seu pai quase se matou, fez a mãe nove novenas mas de nada adiantou, andava de boca em boca que foi boto que a roubou, $[\ldots]$ (IBID, p. 93)

Observa-se, nesse romance, a ambientação proposta pelo poeta na escolha semântica das palavras para dizer que algo trágico acontecerá. A natureza se reveste de figuras simbólicas agourentas: coruja, rã, o rio sem força, nuvens sujas, cauã. Na segunda parte do romance, a menina e o que vai fazer nos são apresentados melhor - lânguida, preguiçosa, vai buscar água no rio. A moça é uma flor que desabrochou antes do tempo, o poema não diz, mas imaginamos essa menina "extemporânea" que, em seu despertar, é alvo do boto porque está nos seus dias de regras: "Bocejo de fogo e forma/ se esboçava esse abio/ duplo, da mulher menina,/ planta agreste do arrepio" (IBID., p. 93).

No desfecho da história, ficamos sabendo que a menina sumiu levada por um boto. Esses animais são referidos no imaginário popular amazônico enquanto seres mágicos e por terem tal característica podem se transformar em homens encantadores e sedutores. A transformação em rapaz que leva a menina para o fundo do rio nos mostra outra faceta revelada no poema: a relação do homem amazônico com o fantástico. Há aceitação de que a jovem tenha sido levada pelo boto e isso causa comiseração e a tristeza nos familiares, mas não estranheza. Estamos, pois, diante do que Tzvetan Todorov (2004) chama de maravilhoso: o irreal irrompe no mundo real. Todorov relaciona o fantástico com a dúvida, enquanto o ribeirinho acredita mesmo nas histórias de boto.

Somanlu, ano 11, n. 1, jan./jun. 2011159 
Para Loureiro (1995, p. 193-194), a irrupção do irreal ou sobrenatural é também uma das formas assumidas pelo estético, esse aspecto do estético chama-se de contemplação devaneante. Nesse caso, a contemplação devaneante faz surgir conceitos e atitudes face ao contemplado. Essa maneira de o homem amazônico se relacionar, conceituar e perceber as coisas que o rodeiam converge para o que Eliade (2006, p. 22) aventa sobre o poder de revelação social-humana presentes nos mitos, pois eles revelam "que o mundo, o homem e a vida têm uma origem e uma história sobrenaturais, e que essa história é significativa, preciosa e exemplar." Não devemos perder de vista, entretanto, que o mito estudado por Eliade diz respeito às sociedades arcaicas, no caso amazônico, a dos índios. A sociedade ribeirinha está distanciada da referida por Eliade, porém alguns aspectos míticos foram preservados nas narrativas dos ribeirinhos.

O que se vê nas imaginações devaneantes que pairam sobre o boto é a presença de refigurações mitológicas que remontam aos deuses gregos: Apolo, pela beleza; Dioniso, associado ao prazer que causa nas mulheres e à subversão a que são levadas; Eros e Tanatos, por ser fonte de amor, beleza e morte.

\section{Memória}

O Romanceiro, na prerrogativa de cantar as cenas amazônicas, traz três textos que irão dar relevância à sabedoria popular atribuída às pessoas mais velhas. Nesses poemas, o traço principal é dado pela ideia de conservação da memória das pessoas idosas que labutam nos rios e florestas amazônicos e que carregam vestígios importantes da cultura oral, o que os configuram como seus principais guardiões.

O romance que abre essa parte chama-se "O homem". As imagens percebidas no poema referem-se ao homem mais velho, que atingiu certa idade, tem mais experiência e sabedoria e, por isso, é respeitado e reverenciado pelos mais novos. A sabedoria desse homem é a mais simples possível, resultado de práticas cotidianas feitas no lugar em que sempre viveu. Temos que a temática da sabedoria dos mais velhos se encontra em qualquer sociedade;

160 Somanlu, ano 11, n. 1, jan./jun. 2011 
entretanto, no universo caboclo, retratado por Elson Farias, o assunto é mostrado de maneira particular na divisão intitulada Três romances do meu tio Luís, sendo o tio Luís uma versão singularizada do homem que vive no e para o rio.

No "Romance das sementes", há visões pormenorizadas dessa temática da sabedoria milenar das pessoas mais velhas. Nesse poema, o tio do eu lírico fazia várias labutas diárias e ritualísticas que antecediam ao dia e hora da "iluminação", que ocorria à época dos finados, em que havia visitas às covas dos entes queridos.

$\mathrm{Na}$ última estrofe do romance, as sementes assumem o sentido de coisas que ele não plantou e, portanto, não colheu. Ele as guarda para esse dia tão importante de visita a seus mortos, como se nesse ato houvesse uma lamentação do que não conseguiu construir em vida: "Inda hoje meu tio vive/ com planos para as sementes/ que até hoje não plantou,/ esperando o bom verão/ a fim de neles plantá-las/ e visitar os parentes,/ as suas velhas sementes/ [...]que ele as trazia para plantar no verão"(IBID., p. 70).

Segundo Bosi (1994), os velhos, nas tribos antigas, tinham lugar de honra no resguardo do bem mais precioso para eles: a tradição, passada de pessoa a pessoa e cuja responsabilidade é dos mais idosos. Tal forma de representação é colocada nos poemas referidos, uma vez que verificamos a presença da memória dos velhos quando narram histórias exemplares que as crianças ouvem com deleite, da feitura de cruzes para prestigiar os mortos queridos e da honra das coisas simples da vida: "Lá pela boca da noite /ele vinha - suas histórias/ nunca mais teriam fim./ Contava coisas incríveis/ para nós todos assim/ meu tio passava a vida/ contando fatos para mim/ [...]" (IBID., p. 70).

Desse modo, verificamos a representação, no Romanceiro, da figura da pessoa idosa e do mestre que nunca saiu de sua terra, mas tem algo a contar e a ensinar. Assim, tal maneira de elaboração da vida da pessoa mais velha que habita nas lonjuras amazônicas está em consonância com a figura dos narradores tradicionais pensados por Benjamin (1994). Para ele, as histórias tradicionais não devem ser simplesmente lidas ou ouvidas, devem ser escutadas e seguidas, pois elas têm um senso prático e utilitário: crescimento moral, su- 
gestão, normas de conduta. A experiência se inscrevendo numa temporalidade comum a várias gerações e que deve ser compartilhada com os mais jovens.

\section{Sexualidade}

Entrelaçada às temáticas até aqui verificadas, encontramos no Romanceiro poemas que perscrutam a força e a beleza sexual de imagens femininas à beira-rio. Para tratar desse assunto, verificaremos como se manifestam essas imagens produzidas pelo poeta, por meio do estudo sobre a imaginação da matéria, a partir dos conceitos constantes de $A$ água e os sonhos, de Gaston Bachelard (1997).

Conforme Bachelard, há duas forças imaginantes na mente humana que carregam um dualismo: a imaginação formal e a imaginação material. A primeira é verificável na superfície das coisas, no que é possível de ser observado, portanto, no que se vê. Para desvendar a segunda força é necessário recorrermos ao primitivo do ser e somente podemos acessá-la quando buscamos o eterno e a profundidade do ser humano, porque tais imagens são retiradas diretamente da matéria e não são perceptíveis à primeira vista. A imaginação material apoia-se nas imagens alimentadas e retiradas diretamente da matéria (ar, água, fogo e terra) e provoca tristeza, alegria, comoção, devaneio, sonho, ou melhor, sentimentos e sensações os mais diversos.

Ao tentar penetrar nas imagens retiradas e/ou produzidas diretamente da matéria, estaremos tentando descobrir as imagens que estão escondidas por trás das que estão à mostra. Para verificar essas representações, Bachelard se debruça sobre algumas criações poéticas que apresentam esse elemento material. Daí, ele revisitar a mítica que se esconde por trás das águas claras, das águas profundas, das águas compostas, da água maternal e feminina, da água violenta e das águas doces, entre outras.

As imagens visualizadas nos poemas referidos se dão no rio. $\mathrm{O}$ rio carrega a representação da água que reflete, refresca, alimenta e dissolve. A água do rio é considerada, igualmente, a água mítica por natureza, pois possibilita o nela mirar-se como se fosse um espelho, uma vez que se move com mais lentidão e

162 Somanlu, ano 11, n. 1, jan./jun. 2011 
menos braveza do que o oceano. O rio tem também um único destino e caminho: parte de sua fonte e vai a um desaguadouro, sendo a força das águas provenientes de sua nascente. Loureiro (1995), como aludido antes, refere-se à água (rio) e à floresta amazônica como possuidores de grandes olhos que espreitam. Algo que está de acordo com o pensamento de Bachelard, quando fala das imagens materiais da água doce (rios, riachos, veios d'água, fontes, arroios), porque somente essas águas têm o poder de refração, trazendo em si um espelho, chamado de "o espelho das águas: a água serve para naturalizar nossa imagem para devolver um pouco da inocência e de naturalidade ao orgulho de nossa contemplação íntima" (BACHELARD, 1997, p. 23).

Ainda de acordo com Bachelard, o rio tem uma função sexual que é a de evocar a nudez natural feminina. Elson Farias, desse modo, ao retratar a mulher em algumas situações cotidianas em que aparece despida ou insinuando nudez, está evocando essas imagens de pureza, sensualidade e sexualidade despertada à beira do rio, trazendo-nos representações míticas consubstânciadas em Afrodite, Eros, Narciso e nas visualizações invertidas ou não da imagem de Ofélia.

Ofélia, personagem de Hamlet, de Shakespeare (1564 - 1616), que é carregada ao sabor das águas do riacho em que se precipita vestida e com a longa cabeleira a agitar-se na água evoca, entre outras imagens, a fluidez das águas correntes, a morte que, após as suas desditas, ocorre no rio e, neste caso específico, a loucura que a conduziu para a morte. Não devemos esquecer que Ofélia caiu de um salgueiro que tinha os galhos inclinados, refletindo as próprias folhas no espelho do riacho.

Sendo a água um espelho que reflete o que está a sua volta, pode ser relacionada à metáfora de Narciso. Não exatamente na acepção comumente conhecida do narcisismo, mas sim ao fato, ainda segundo Bachelard, de que, mirando-nos na água, conseguimos perscrutar a alma humana em várias nuances e ambivalências. Foi o que aconteceu a Narciso, e que serve para alimentar a imaginação material humana, pois ele, ao mirar-se no espelho das águas, conseguiu enxergar seu duplo poder viril e feminino e, principalmente, viu-se diante da voz evocadora de Eco, um sendo o outro: "Ela é Ele". Isso 
põe em questionamento a dualidade presente nos seres humanos - somos constituídos, ao mesmo tempo, da psique feminina e masculina, carregamos, portanto, essa marca.

Assim, o rio, com seu poder de refração, assume o mito de Narciso. É nele que irão se produzir as imagens materiais presentes em alguns poemas do Romanceiro: o rio alimenta, dessedenta, refresca e sexualiza. Nele, morre-se e vive-se a um só tempo. No "Romance da mimosa pudica", o refrão pede para a personagem Maria fechar a porta porque o pai morrera. Mimosa é o nome de uma planta rasteira que fecha as folhas ao ser tocada. A ordem de fechar a porta é dada à planta; esta, metonimicamente, é Maria, que é moça casta, mas a natureza reverbera-se, assumindo a sexualidade contida de Maria/mimosa. $\mathrm{Na}$ morte do pai, natureza e Maria fundem-se, tudo vibra, arde: manhã, rosas, cravos. Símbolos fálicos não são esquecidos (talas, espadas, serras hirsutas), para ilustração da sexualidade. Observam-se também referências a velório e a tristeza, num incessante jogo dos contrários - o amor em confronto com a morte (Eros versus Tanatos):

Entre talas como espadas

e serras hirsutas, duras, vibram as flores vermelhas com seus desejos de vida, os cravos crus ardem vivos com seus anseios de sangue, as rosas na grande graça, grande graça da beleza, $[\ldots]$

"Maria, fecha a porta que teu pai morreu."

Suas folhas se contraem.

Com pudor de viver, chora. (IBID., p. 47) 
Ao final, Maria, tal como as folhas, se contraí, e chora. A beleza do poema é ressaltada por um jogo erótico metonímico e contrário: Maria e a natureza se revelam enquanto uma só; os signos antitéticos evocam, ao mesmo tempo, a sexualidade recatada e em flor da personagem.

$\mathrm{Na}$ trama da sexualidade e sensualidade despertada, Elson Farias elege, em seguida à mimosa pudica, na divisão Três romances da infância, dois poemas de contornos sensuais e um metalinguístico. No geral, o que se vislumbra nesses poemas é a libido da criança sendo despertada por imagens que flagrou à beira-rio.

O primeiro é o poema de abertura e que serve de pórtico para os demais poemas dessa divisão: "A mulher". Esse poema nos remete à Ofélia de Shakespeare, pois, em consonância com Bachelard (1997), não há sinédoque poética mais evocativa do que uma cabeleira flutuando. Tal imagem, na imaginação da matéria, é recorrente porque a ondulação da cabeleira é dinâmica, assim como a água, não sendo necessário, desse modo, aparecer toda a imagem de Ofélia para que percebamos seu surgimento: "A mulher violava as águas/ com as tranças dos cabelos, / perfumava o rio rosa/ como um cardume de peixes./ Depois recolhia o corpo,/ nu, rendilhado de sol,/ e afagava com os braços/ aquelas estrelas claras" (Ibid., p. 55).

A nudez feminina, as tranças, o reflexo do céu nos olhos lavados, o mergulho no rio, a cobertura dos seios alvos com os braços. Visualizamos toda a cena, o rio sendo o grande espelho, comungando momento do banho despretensioso, de puro sensualismo. As tranças/cabeleira e a própria personagem flutuando, de "bubuia", usando a expressão amazônica para referir-se ao ato de flutuar, trazem à imaginação devaneante a figura das ninfas e de Ofélia. A representante amazônica do mito e/ou imagem de Ofélia associada a uma cabeleira flutuante, consoante Santiago (1986), é a mãe-d'água. Dessa forma, a imagética que associa água e cabeleira nos remete a essa figura lendária dos rios.

Os dois últimos quadros escolhidos para mostrar a marca de sensualidade e sexualismo surpreendida no eu lírico elsoniano, encontram-se no "Romance dos recém-casados" e no "Romance da moça e o peixe". Ambos dão 
conta de acontecimentos de envergadura social marcante que ocorrem no Amazonas. No primeiro, a dificuldade do casamento nas vilas, porque ali não chega padre; no segundo, o caso notável da jovem que foi deflorada por um candiru, peixe pequeno que, na Amazônia, pode entrar por orifícios das pessoas que tomam banho nuas nos rios.

O "Romance da moça e o peixe" conta uma história. A personagem é Eulália, irmã de Rosa Maria, vinte anos, lava roupa à beira-rio. Visualizamona com uma perna estendida e outra encurvada e, nesse movimento, as coxas aparecem sob o sol. A natureza, porém, compartilha com o leitor os prenúncios de que algo ocorrerá, pois os botos passam por perto em bizarria, a paisagem treme. O veredito é dado: “- pobre Eulália que era virgem/ e que não mais o seria!/ O peixe feriu-lhe o sonho/ no corpo que se perdia./ Isto aconteceu no rio,/ no verão, num certo dia” (IBID, p. 100).

O que se verificou é que $\mathrm{O}$ Romanceiro é um todo ordenado e as temáticas trabalhadas conseguem reproduzir claramente a proposta do poeta: cantar a terra, o povo a partir de situações e fatos simples da vida cotidiana de seu habitante mais representativo, o caboclo.

A unidade temática do livro pode ser percebida a partir do primeiro e do último poema, em que o eu poético enseja de maneira particular desnudar o ambiente amazônico pela palavra certa, elaborada e definitiva. Mais que narrar, quer mostrar aos desavisados que, neste lugar, vibram vidas simples e ricas, que tentam se harmonizar diante do inexorável e implacável vai e vem das águas do rio: "Quero usar do verso força/para mostrar sem narrar". Essa proposta termina na última fala do livro com o poema "A palavra": é o momento em que o bardo fecha a sua narrativa depois de muito esforço, pois a palavra teima em não querer sair, mas ele consegue. A palavra é integradora: por meio dela e por ela, o eu poético colhe e deixa sonhos, nasce e morre, ganha e perde possibilidades. O rio, pela palavra, assim como a vida, flui independente de qualquer obstáculo. $\mathrm{O}$ homem ribeirinho e o rio possuem a imagem da fluidez da vida e da morte: "É corpo do homem/ que não se acaba/ rio que integra/ esta palavra” (FARIAS, 1990, p. 89).

166 Somanlu, ano 11, n. 1, jan./jun. 2011 
Retomando a discussão inicial feita sobre a escrita regionalista cunhada de "cor local", que privilegia peculiaridades de dada região, o que se infere é que, sendo local ou não, o que o artista representa, no geral, faz parte de sua cultura ou do lugar onde habita. Se pensarmos a cultura enquanto "um conjunto de sistemas simbólicos, à frente dos quais situam-se a linguagem, as regras matrimoniais, as relações econômicas, a arte, a ciência, a religião" (MAUSS, 2003, p. 19), podemos sugerir que as representações simbólicas sociais presentes no Romanceiro apontam para uma maneira de perceber aspectos da realidade circunscrita às peculiaridades do habitante regional. O recorte temático privilegiado pelo escritor não deve invalidar a maneira escolhida para representar essa realidade porque, conforme vimos, as temáticas regionais são perpassadas por idiossincrasias humanas e míticas que podemos encontrar em qualquer lugar, no entanto, as representações são eminentemente amazônicas.

Considerando, consoante Boaventura de Souza Santos (2006, p. 191), a "representação como mais uma forma de olhar", temos, nos poemas escolhidos para leitura, temáticas amazônicas, que se constituem numa das possibilidades de verificação sobre o homem, sendo a reconstrução do significante e significado, por meio do poético, mais uma forma de representação e reduplicação da memória coletiva.

Márcio Souza, em A expressão Amaz̧onense (2003, p. 207), diz que Elson Farias é um poeta que, ao escrever, consegue abranger "a paisagem, a geografia humana, a força de trabalho, a miséria e a alegria de ser ribeirinho, de ser caboclo na imensidão amazônica." Isso pode ser confirmado pelo que foi tratado no texto, visto que o autor em questão não esquece os principais aspectos que o imaginário assume no ambiente dos grandes rios regionais. A vida do povo dos beiradões é a história que Elson Farias recria, sendo que as imagens do rio são investigadas sob vários ângulos: o caboclo, os mistérios, as lendas, o viver simples do povo, as pescarias, a labuta diária, nada disso foi esquecido na ótica singular do poeta, na reprodução de quadros inteiramente locais. 


\section{Notas}

${ }^{1}$ A expressão “caboclo” é utilizada por Eduardo Galvão (1976), na obra Santos e Visagens, para referir-se às pessoas que moram no meio rural amazônico. Com a mesma designação, nós a usamos no presente trabalho.

${ }^{2}$ Ao fazer referência às subdivisões presentes no Romanceiro, usamos todas as letras grafadas em maiúsculas, obedecendo, assim, à forma apresentada no livro-base: DA MORTE PELA ÁGUA, DA CHUVA E SEUS MEDOS, DA FARTURA DAS ÁGUAS, SEIS ROMANCES DE OUTRAS SORTES etc.

\section{Referências}

ARISTÓTELES. Arte poética. Trad. Pietro Nassetti. São Paulo: Martin Claret, 2004.

BACHELARD, Gaston. A água e os sonhos: ensaio sobre a imaginação da matéria. Trad. Antonio de Pádua Danesi. São Paulo: Martins Fontes, 1997.

BENJAMIN, Walter. O narrador: considerações sobre a obra de Nikolai Leskov. In: - Magia e técnica, arte e política: ensaios sobre literatura e história da cultura. Trad. Sérgio Paulo Rouanet. 7. ed. São Paulo: Brasiliense, 1994.

BOSI, Eclea. Memória e sociedade: Lembranças dos velhos. 3. ed. São Paulo: Companhia das Letras, 1994.

ELIADE, Mircea. Mito e realidade. 6. ed. Trad. Pola Civelli. São Paulo: Perspectiva, 2006 (Debates, 52).

FARIAS, Elson. Romanceiro. 2. ed. Rio de Janeiro: José Olympio, 1990. Memórias literárias. Manaus: Valer/Uninorte, 2006.

GALVÃO, Eduardo. Santos e visagens: um estudo da vida religiosa de Itá, Baixo Amazonas. 2. ed. São Paulo: Ed. Nacional, 1976.

GOLDSTEIN, Norma. Versos, Sons, Ritmos. 13. ed. São Paulo: Ática, 2000.

168 Somanlu, ano 11, n. 1, jan./jun. 2011 
LOUREIRO, João de Jesus Paes. Cultura amazônica: uma poética do imaginário. Belém: Cejup, 1995.

MAUSS, MARCEL. Sociologia e Antropologia. Trad. Paulo Neves. São Paulo: Cosac \& Naify, 2003.

MOISÉS, Massaud. Dicionário de termos literários. 14. ed. São Paulo: Cultrix, 1999.

SANTIAGO, Silviano. O narrador pós-moderno. In: Nas malhas da letra. São Paulo: Companhia das Letras, 1989.

SANTIAgO, Socorro. Uma Poética das Águas. Manaus: Puxirum, 1986.

SANTOS, Boaventura de Souza. A gramática do tempo: para uma nova cultura política. São Paulo: Cortez, 2006 - (Coleção para um novo senso comum, v. 4).

SOUZA, Márcio. A expressão amaz̧onense. 2. ed. Manaus: Editora Valer, 2003. TAVARES, Hênio. Teoria literária. 7. ed. Belo Horizonte: Itatiaia, 1981. TODOROV, Tzvetan. Introdução à literatura fantástica. Trad. Maria Clara Correa Castello. 3. ed. São Paulo: Perspectiva, 2004 (Coleção Debates; 98). 